\title{
RAGAM BAHASA DI KECAMATAN PAKISJAYA \\ KABUPATEN KARAWANG \\ (Kajian Sosiolinguistik)
}

\author{
Nanang Suhendar \\ Program Studi Pendidikan Bahasa dan Budaya Sunda SPs UPI \\ Pos-el: nanangsuhendar07@gmail.com
}

\begin{abstract}
Abstrak
Penelitian ini dilatarbelakangi adanya ragam bahasa yang hidup di masyarakat Kecamatan Pakisjaya Kabupaten Karawang. Pakisjaya berada di perbatasan antara Kabupaten Bekasi dan laut Jawa yang masyarakatnya heterogen baik dalam masalah bahasa maupun budayanya. Penelitian ini mempunyai tujuan untuk mengetahui ragam bahasa yang dipakai oleh masyarakat Pakisjaya yang memakai dua bahasa yaitu bahasa Betawi dan bahasa Sunda, alih kode apa saja yang dipakai sebagai pengaruh dari adanya pemakaian dua bahasa tersebut, campur kode apa saja yang dipakai sebagai pengarh dari pemakaian dua bahasa tersebut, dan faktor apa saja yang mempengaruhi adanya ragam bahasa yang hidup di masyarakat Pakisjaya menggunakan kajian Sosiolinguistik. Penelitian ini menggunakan metode kualitatif dengan teknik deskriptif. Sumber data dalam penelitian ini yaitu ragam bahasa yang dipakai masyarakat Pakisjaya yang terdiri dari tujuh profesi sebagai wakil lapisan sosial masyarakatnya. Teknik pengambilan data yang dipakai yaitu wawancara dan observasi langsung. Ada beberapa instrumen yang dipakai dalam penelitian ini diantaranya kamera, alat perekam, dan pedoman wawancara. Berdasarkan hasil penelitian ada enam ragam bahasa yang dipakai masyarakat Pakisjaya diantaranya ragam bahasa akrolek, basilek, kolokial, argot, slang, dan jargon. Kemudian alih kode yang ada yaitu alih kode intern terdiri dari peralihan kode bahasa Sunda ke bahasa Betawi. Sedangkan campur kode yang ada yaitu campur kode ke dalam terdiri dari bercampurnya bahasa Betawi dengan kata bahasa Sunda sebagai akibat dari penggunaan bahasa Betawi dan bahasa Sunda dalam komunikasi seharihari. Terakhir ada dua faktor yang menyebabkan adanya ragam bahasa yaitu karena lektak geografis Pakisjaya sebagai daerah perbatasan dan ragam bahasa diperlukan masyarakat sebagai media penyaluran bahasa dalam komunikasi, misalnya dalam komunikasi profesi dan komunitas. Kesimpulannya ragam bahasa sanggat memberi manfaat bagi masyarakat untuk saling memahami bahasa satu dengan lainnya terutama untuk daerah yang heterogen.
\end{abstract}

Kata Kunci: Ragam Bahasa, Alih Kode dan Campur Kode, Sosiolinguistik.

\section{LANGUAGE VARIETY IN PAKISJAYA DISTRICT KARAWANG REGENCY (A Sociolinguistic Research)}

\begin{abstract}
Abstrak
This research is based on the varieties of languages that exist in society, especially in Pakisjaya district Karawang regency. Pakisjaya is laid in the border of Bekasi Regency and Java Ocean. The language and culture is heterogenic. This study is aimed to collect the varieties of languages that is used by Pakisjaya residents. They use two kinds of languages: Betawi and Sundanese. This research used qualitative method with descriptive technique. Data source in this research is the varieties of languages that is used by Pakisjaya people
\end{abstract}


which consist of seven professions as representative of society. The technique of collecting data is interview and obvious observation. There are some instruments that become supporting units to sustain this research; they are camera, sound recorder, and interview manual. Based on the result of research there are six varieties of languages that is used by Pakisjaya people they are; Akrolect, Basilect, colloquial, Argot, Slang, and Jargon. Furthermore, the code switching covers internal code consisting of the transfer from Sundanese to Betawi. In addition, code mixing covers the mixing of Betawi and Sundanese since there is an influence of both languages in the daily conversation. Lastly, there are two factors that affect language varieties. First, it is the geographical factor of Pakisjaya as a border area. Second, it is language varieties needed by people as language platform media in communication, such as in occupation and community. The research concludes that language varieties is beneficial for the society to understand each language to another language especially for heterogenic area.

Keywords: Language variety, Code Switching, Code Mixing, Sociolinguistic.

\section{PENDAHULUAN}

Secara geografis wilayah Jawa Barat merupakan daerah yang luas yang menjadikan daerahnya berbatasan dengan daerah lain seperti di sebelah barat berbatasan dengan Provinsi DKI Jakarta dan Banten, serta sebelah Timur berbatasan dengan Provinsi Jawa Tengah. Kabupaten dan kota yang berbatasan langsung dengan provinsi tersebut diantaranya Kabupaten Bogor, Kabupaten Bekasi, Kabupaten Sukabumi, Kota Depok, Kabupaten Cirebon, Kabupaten Kuningan, Kabupeten Ciamis dan Kota Banjar. Adanya beberapa wilayah yang berbatasan langsung dengan wilayah lain menjadikan daerah perbatasan tersebut mengalami perubahan budaya.

Perubahan budaya yang sangat terlihat diantaranya adalah bahasa. Adanya perbedaan bahasa dari dua wilayah tersebut akan memungkinkan suatu bahasa berkembang menjadi bahasa yang baru akibat adanya percampuran bahasa ataupun pertukaran kode-kode bahasa tersebut. Dalam masyarakat yang heterogen akan timbul variasi-variasi bahasa sebagai akibat dari perbedaan latar belakang pemakaian bahasa dari masing-masing penutur. Ada dua faktor yang menentukan dalam komunikasi yaitu faktor situasional dan faktor sosial (Rene Appel dalam
Pateda. 1987, hal. 15-16). Faktor situasi turut mempengaruhi pembicaraan dalam pemilihan kata-kata dan bagaimana caranya mengkode, sedangkan faktor sosial turut menentukan bahasa yang dipergunakan. Faktor sosial mencakup umur, jenis kelamin, latar belakang ekonomi, tempat tinggal, dan sebagainya.

Ragam bahasa bisa diartikan sebagai variasi penggunaan bahasa, hal ini sesuai dengan yang dikemukakan oleh Suwito (1983, hal. 148) ragam bahasa adalah suatu istilah yang dipergunakan untuk menunjuk salah satu dari sekian variasi yang terdapat dalam pemakaian bahasa. Begitu juga menurut Chaer \& Leonie Agustina (2004, hal. 62) ragam bahasa adalah keragaman bahasa yang dilakukan oleh masyarakat heterogen. Ragam bahasa bisa dibagi menjadi dua yaitu ragam bahasa yang dilihat dari segi pemakai bahasa dan ragam bahasa yang dilihat dari segi pemakaian bahasa. Hal ini sesuai dengan yang diungkapkan Sudaryat (2004, hal. 11) ragam bahasa dibagi menjadi dua yaitu dari segi pemakai dan pemakaian. Dilihat dari segi pemakai, ragam bahasa dibagi dua yaitu idiolek dan dialek. Idiolek adalah bahasa yang dimiliki oleh perorangan atau individu, dan dialek adalah bahasa yang dimiliki oleh kelompok masyakarat. Dialek dibagi lagi menjadi tiga yaitu regiolek, 
sosiolek, dan kronolek. Sedangkan dari segi pemakaian bahasa, ragam bahasa dibagi menjadi tiga yaitu berdasarkan tujuan pemakaian bahasa, tingkat kebakuan pemakaian bahasa, dan medium pemakaian bahasa. Ragam bahasa dilihat dari tujuan pemakaian bahasa dibagi menjadi tiga yaitu bahasa sehari-hari, bahasa keilmuan, dan bahasa kesastraan. Lalu menurut tingkat kebakuan pemakaian bahasa, ragam bahasa dibagi menjadi dua yaitu bahasa baku dan bahasa tidak baku. sedangkan menurut medium pemakaian bahasa, ragam bahasa dibagi menjadi dua yaitu bahasa lisan dan bahasa tulisan.

Dalam penelitian ini, dibahas ragam bahasa berdasarkan pemakai bahasa. Hal ini dilatarbelakangi adanya ragam bahasa di Kecamatan Pakisjaya Kabupaten Karawang yang daerahnya berbatasan langsung dengan Kabupaten Bekasi dan laut Jawa, yang mengakibatkan adanya keberagaman bahasa dan budaya di masyarakatnya. Masyarakat yang berbatasan dengan laut Jawa mayoritas menggunakan bahasa Jawa, sedangkan masyarakat yang berbatasan dengan Kabupaten Bekasi mayoritas berbahasa Betawi sehingga membuat masyarakat Pakisjaya mempunyai tiga bahasa dalam komunikasi sehari-hari.

Dengan adanya pemakaian tiga bahasa yang berbeda ini menyebabkan adanya kontak bahasa di masyarakat Pakisjaya. Kontak bahasa yaitu proses saling mempengaruhi antara kode satu bahasa dengan bahasa lain, wujud kontak bahasa ini bisa berupa alih kode dan campur kode. Alih kode yaitu penggunaan variasi bahasa lain dalam satu peristiwa bahasa sebagai strategi untuk menyesuaikan diri dengan peran atau situasi lain, atau karena adanya partisipan lain (Kridalaksana. 2009, hal. 9), sedangkan campur kode yaitu kedaan bercampurnya satu kode bahasa dengan kode bahasa lain yang disebabkan oleh situasi dan kebiasaan (Nababan 1991, hal. 32), begitu juga menurut Kridalaksana
(2009, hal. 40) campur kode yaitu penggunaan satu bahasa dari satu bahasa ke bahasa lain untuk memperluas gaya bahasa atau ragam bahasa, termasuk didalamnya pemakaian kata, klausa, idiom, sapaan, dsb. Hal ini sesuai dengan yang dikemukakan oleh Hudson (1998, hal 51, 53) berbagai ragam bahasa mungkin bercampur dalam rangkaian ujaran yang sama. Istilah percampuran ragam bahasa ini diistilahkan berupa alih kode dan peminjaman (campur kode). Selain itu, rasa penasaran peneliti mengenai faktor apa yang menyebabkan adanya ragam bahasa di Kecamatan Pakisjaya Kabupaten Karawang membuat peneliti mengadakan penelitian ini menggunakan kajian sosiolinguistik.

Teori sosiolinguistik yang digunakan dalam penelitian ini adalah teori yang dibahas oleh Abdul Chaer (2004) mengenai sosiolinguistik sebagai cabang ilmu yang menjelaskan ciri-ciri ragam bahasa dan menentukan korelasi ciri ragam bahasa dengan ciri sosial masyarakat hususnya dalam komunikasi. Ada beberapa unsur dalam komunikasi masyarakat diantaranya pembicara, pendengar, tempat berbicara, isi pembicaraan, suasana pembicaraan, dan lainnya.

\section{METODE}

Penelitian ini membahas ragam bahasa yang hidup di masyarakat Kecamatan Pakisjaya Kabupaten Karawang. Sumber data dalam penelitian ini adalah ragam bahasa sosiolek yang ada di masyarakat Pakisjaya yang terdiri dari ragam bahasa akrolek, basilek, vulgar, slang, kolokial, jargon, argot, dan ken. Hal ini sesuai dengan yang dikemukakan oleh Maleong (2007, hal. 157) sumber data utama dalam penelitian kualitatif adalah kumpulan kata dan tindakan. Sedangkan partisipan dalam penelitian ini adalah masyarakat Pakisjaya yang mempunyai kriteria (1) masyarakat asli Pakisjaya, (2) 
lelaki dan perempuan, dan (3) usia minimal 17 tahun.

Berdasarkan kriteria partisipan di atas, partisipan yang menjadi narasumber dalam penelitian ini adalah guru, siswa, pegawai pemerintah, pedagang, nelayan, petani, dan tokoh agama. Tempat penelitian yaitu di Kecamatan Pakisjaya Kabupaten Karawang yang terdiri dari delapan desa, yaitu desa Tanjung Pakis, désa Tanjung Mekar, désa Tanjung Bungin, désa Solokan, désa Tanah Baru, désa Teluk Jaya, désa Teluk Buyung, dan désa Telagajaya.

Untuk mengumpulkan data diperlukan instrumen dan tehnik. Tehnik merupakan serangkaian langkah dan strategi untuk memahami keadaan secara sistematis (Ratna. 2011, hal. 34). Tehnik yang digunakan dalam penelitian ini yaitu berupa tehnik wawancara, dan tehnik observasi, sedangkan instument yang digunakan yaitu berupa pedoman wawancara, alat perekam, dan kamera

Penelitian ini menggunakan metode kualitatif dengan analisis deskriptif. Metode kualitatif ini digunakan untuk menganalisis objek yang yang tidak bisa diukur menggunakan angka. Ragam bahasa merupakan objek yang non eksak, artinya hanya bisa didekskripsikan menggunakan kata-kata.

Metode kualitatif digunakan dalam penelitian ini dilatarbelakangi oleh sipat metode kualitatif. Ada lima sifat metode kualitatif yaitu (1) bersifat induktif, maksudnya mempunyai dasar logika yang jelas, (2) memahami pola hidup manusia berdasarkan sudut pandang penulis, sehingga penulis mampu mendeskripsikan hasil penelitian secara jelas, (3) lebih mementingkan proses penelitian dari pada hasil penelitian, (4) sipatnya humanistis, dan (5) segala aspek kehidupan yang ada di masyarakat dianggap penting. Berdasarkan sipat metode kualitatif tersebut penulis mampu mencapai tujuan penelitian yang ingin memahami pola ragam bahasa yang hidup di masyarakat Pakisjaya dan mendeskripsikannya secara jelas.

Penelitian yang menggunakan analisis deskriptif tidak bisa lepas dari metode kualitatif yang dianggap efektif untuk menemukan fakta atas data penelitian. Hal ini disampaikan oleh Suyanto (2006, hal. 80) dalam empat langkah penelitian kualitatif. Empat langkah yang dimaksud adalah (1) mengumpulkan data, (2) menganalisis data, (3) menapsirkan data, dan (4) membuat kesimpulan.

Berdasarkan langkah-langkah di atas, point menafsirkan data dalam penelitian ini menggunakan analisis sosiolinguistik yaitu menempatkan ragam bahasa sosiolek sesuai dengan kedudukan dan maknanya menurut masyarakat.

\section{HASIL DAN PEMBAHASAN}

Berdasarkan hasil penelitian mengenai ragam bahasa di Kecamatan Pakisjaya Kabupaten Karawang, ada enam ragam bahasa yang ditemukan. Keenam ragam bahasa tersebut adalah ragam bahasa akrolek, basilek, kolokial, argot, slang, dan jargon yang didapat dari ketujuh profesi yang telah ditentukan sebagai sumber data dalam penelitian ini. Tidak semua ragam bahasa ada dalam satu profesi, supaya lebih jelas peneliti akan memaparkan hasil penelitiannya.

Ragam bahasa yang pertama adalah ragam bahasa akrolek, ragam bahasa akrolek adalah ragam bahasa yang dianggap mempunyai nilai kesopanan yang sangat tinggi. Ada empat profesi yang ditemukan memakai ragam bahasa akrolek yaitu guru, pegawai pemerintah, petani dan tokoh agama. Ragam bahasa akrolek seperti kata muhun hampir sama ditemukan dan dipakai di empat profesi tersebut. Dari keempat profesi yang ditemukan memakai ragam bahasa akrolek, profesi guru yang paling banyak menggunakan ragam bahasa akrolek dengan kata yang beragam seperti abdi, muhun, ngartos, badé, dll. Hal ini 
cenderung disebabkan karena latarbelakang profesi guru yang memiliki pendidkan tinggi dan juga sekaligus guru sebagai contoh teladan di sekolah yang mengharuskan menggunakan tutur bahasa yang baik.

Ragam bahasa yang kedua adalah ragam bahasa basilek, kebalikan dari ragam bahasa akrolek, ragam bahasa basilek dianggap lebih rendah atau tidak sopan oleh pemakainnya. Dalam penelitian ini ragam bahasa basilek hanya ditemukan di profesi petani. Hal ini disebabkan karena dalam komunikasi sehari-hari profesi petani tidak mengharuskan menggunakan bahasa formal dan cenderung menggunakan bahasa langsung, ini menjadikan ragam bahasa akrolek lebih sering dipakai karena lebih sederhana dan sekaligus berupa cerminan keakraban, karena ragam bahasa akrolek digunakan oleh petani yang memang sudah saling mengenal dan akrab.

Ragam bahasa yang ketiga adalah ragam bahasa argot, ragam bahasa argot adalah ragam bahasa yang digunakan oleh sekelompok orang dalam profesi tertentu. Berdasarkan hasil penelitian dari ketujuh profesi yang diteliti semuanya memiliki ragam bahasa argot. Hal ini disebabkan karena ragam bahasa argot diperlukan untuk mempermudah dalam komunikasi profesinya masing-masing, misalnya profesi guru dalam kominikasinya di lingkungan sekolah dan dengan sesama guru, kata-kata yang digunakannya berkaitan dengan profesi dan pekerjaannya yaitu diantaranya kata kurikulum, admisitasi, RPP, silabus, UTS, UAS, PR, dll. Siswa kata-kata yang berkaitan dengan profesinya yaitu kata $P R, U T S, U A S$, dll. Profesi pegawai pemerintah kata-kata yang berkaitan dengan profesinya yaitu kata penyuluh, minggon desa, minggon kecamatan, dll. Profesi pedagang kata-kata yang berkaitan dengan profesinya yaitu kata anak buah, kasbon, ceklik, ngoper, dll. Profesi nelayan kata-kata yang berkaitan dengan profesinya yaitu kata jaring, pancing, lelang, dll. Profesi petani katakata yang berkaitan dengan profesinya yaitu kata arit, nandur, ngelektor nyawah, dll. Profesi tokoh agama kata-kata yang berkaitan dengan profesinya yaitu kata amil, ajengan, tilawah, dll.

Ragam bahasa keempat adalah ragam bahasa jargon, ragam bahasa jargon adalah ragam bahasa yang digunakan oleh kelompok sosial tertentu untuk menyampaikan maksud kelompok tersebut. Ragam bahasa jargon dalam penelitian ini hanya ditemukan dalam profesi pegawai pemerintah. Hal ini disebabkan karena hanya profesi pegawai pemerintah yang kadang mengharuskan memiliki kata-kata atau semboyan untuk mengajak dan menarik perhatian masyarakat demi tercapainya visi misi yang diharapkan, misalnya dalam penelitian ini yang diwakili dinas BKKBN memiliki jargon yaitu dua anak lebih baik. Selain serangkain program-program yang dilaksanakan dinas terkait, diharapkan dengan adanya jargon tersebut lebih bisa memotivasi dan juga terealisasinya tujuan dengan baik di masyarakat.

Kalima ragam bahasa kolokial, ragam bahasa kolokial adalah ragam bahasa yang digunakan masyarakat dalam komunikasi sehari-hari, sering juga disebut sebagai bahasa sehari-hari. Dalam penelitian ini ragam bahasa kolokial ditemukan di tujuh profesi yang diteliti. Ragam bahasa kolokial yang ditemukan di tujuh profesi tersebut merupakan bahasa sehari-hari masayarakat Pakisjaya yaitu bahasa Betawi misalnya kalo, cuman, ga, ngikut, dll.

Keenam ragam bahasa yang terakhir adalah ragam bahasa slang, ragam bahasa slang adalah ragam bahasa yang bersifat khusus dan rahasia hanya pemakainya yang dapat memahami makna dari ragam bahasa ini dan biasanya bersifat temporal tergantung kesepakatan sejauh mana bahasa ini masih efektif untuk digunakan. Dalam penelitian ini profesi pedagang dan 
siswa yang mempunyai ragam bahasa slang. Hal ini disebabkan karena profesi pedagang memang membutuhkan kodekode rahsia dalam perdagangan yang hanya cukup diketahui oleh para pedagang dan tidak untuk dimegerti oleh pembeli, misalnya $A$ seribu, $B$ dua ribu, $C$ tiga ribu, terus sampe $J$ itu sepuluh ribu. Sedangkan siswa, mereka menggunakan istilah atau kata-kata yang berkembang di lingkungannya, biasanya bersifat umum di kalangan siswa dan terkadang hilang dan berganti seiring perubahan waktu dan lingkungan, misalnya kata alay, cabecabean, dll.

Berdasarkan hasil penelitian di atas keenam ragam bahasa yang hidup di Kecamatan Pakisjaya Kabupaten Karawang membentuk suatu pola alih kode dan campur kode. Alih kode adalah perlihan kode bahasa satu ke bahasa yang lain sebagai contoh peralihan dari bahasa Sunda ke bahasa Indonesia dikarenakan peralihan topik pembicaraan, sementara campur kode adalah pencampuran suatu kode bahasa dengan bahasa lain contohnya pencampuran bahasa Sunda dengan bahasa Indonesia dalam suatu percakapan.

Dalam penelitian ragam bahasa ini dikarenakan menggunakan metode wawancara dalam pengambilan datanya maka memungkinkan adanya alih kode dan campur kode, untuk itu peneliti juga menganalisis adanya alih kode dan campur kode masyarakat Kecamatan Pakisjaya Kabupaten Karawang.

Ditemukan 36 data alih kode dari masyarakat Kecamatan Pakisjaya Kabupaten Karawang. Dari data yang ditemukan peralihan kode bahasa tersebut terdiri dari tiga bahasa yang hidup dalam komunikasi masyakaratnya yaitu bahasa Betawi, bahasa Indonesia dan bahasa Sunda. peralihan kode ini terdiri dari peralihan bahasa Sunda ke bahasa Betawi, peralihan bahasa Sunda ke bahasa Indonesia, dan sebaliknya. Dari 36 data yang ada, kebanyakan peralihan terjadi dari bahasa Sunda ke bahasa Betawi. Ini dialami ketika peneliti berusaha mengajak partisipan berkomunikasi dalam percakapan bahasa Sunda tetapi partisipan yang memang berbahasa Betawi terus mengalihkan percakapan dalam bahasa betawi. Begitupun ketika partisipan mengalihkan kode ke dalam bahasa Indonesia. Masyarakat Pakisjaya yang dominan menggunakan bahasa Betawi tentu mempunyai pembendaharaan kosa kata bahasa Sunda yang sangat sedikit, terkadang mereka paham dengan bahasa Sunda yang diucapkan orang lain tetapi tidak bisa membalas percakapan dengan bahasa Sunda.

Sedangkan campur kode yang ditemukan dalam penelitian ini ada 38 data yang membentuk empat pola campur kode yaitu bahasa Betawi bercampur dengan bahasa Sunda, bahasa Sunda bercampur dengan bahasa Indonesia, bahasa Sunda bercampur dengan bahasa Betawi, dan bahasa Indonesia bercampur dengan bahasa Sunda. yang paling banyak ditemukan adalah pola bercampurnya bahasa Indonesia dengan bahasa Sunda dan bercampurnya bahasa Betawi dengan bahasa Sunda. Seperti yang sudah dijelaskan sebelumnya masyarakat Pakisjaya yang menggunakan bahasa Betawi dan bahasa Indonesia dalam komunikasi sehari-hari tetapi juga mempunyai pengetahuan mengenai bahasa Sunda memungkinkan adanya percampuran dari ketiga bahasa tersebut.

Dari hasil penelitian di atas didapat beberapa faktor yang menyebabkan adanya ragam bahasa yang hidup di masyarakat Pakisjaya yaitu (1) faktor geografis Pakisjaya yang ada di daerah perbatasan menjdikan wilayahnya mempunyai penduduk yang heterogen baik bahasa maupun budayanya, dan (2) factor kebutuhan masyarakat, masyarakat dalam komunikasinya memerlukan medium untuk membantu dalam komunikasi sehari-hari, komunikasi dalam profesinya dan 
komunikasi dengan komunitas atau kelompok tertentu.

Sosiolek adalah ragam bahasa yang melihat bahasa dari keadaan sosial masyarakatnya yang berhubungan dengan status sosial, golongan, dan kelas sosial pemakainnya. Sosiolek dibagi menjadi delapan yaitu akrolek, basilék, vulgar, slang, kolokial, jargon, argot, jeung ken.

Berdasarkan hasil analisis di atas intensitas ragam bahasa yang ditemukan ada 38 data ragam bahasa akrolek yang terdiri dari 30 data dari profesi guru, satu data dari pegawai pemerintah, empat data dari petani, dan tiga data dari tokoh agama. Ragam bahasa yang kedua adalah basilek, didapat 23 data yang didapat dari profesi petani. Yang ketiga ragam bahasa kolokial, didapat 185 data yang terdiri dari 14 data dari profesi guru, 37 data dari siswa, 12 data dari pegawai pemerintah, 47 data dari pedagang, 44 data dari profesi nelayan, 10 data dari petani, dan 21 data dari tokoh agama. Yang keempat ragam bahasa argot, didapat 250 data yang terdiri dari 58 data dari profesi guru, lima data dari siswa, 40 data dari pegawai pemerintah, 32 data dari pedagang, 43 data dari profesi nelayan, 68 data dari petani, dan 24 data dari tokoh agama. Kelima ragam bahasa slang, didapat 21 data yang terdiri dari 16 data dari siswa dan lima data dari pedagang. Keenam ragam bahasa jargon yang hanya ada satu data yaitu didapat dari pegawai pemerintah.

Dari hasil pembahasan di atas terlihat ragam bahasa yang paling banyak ditemukan adalah ragam bahasa argot dan ragam bahasa kolokial, keduanya ditemukan di tujuh profesi yang diteliti. Hal ini dikarenakan ragam bahasa argot sebagai ragam bahasa profesi tentu akan dimiliki oleh setiap profesi dalam membantu komunikasinya, sedangkan ragam bahasa kolokial juga banyak ditemukan karena ragam bahasa kolokial merupakan ragam bahasa yang digunakan dalam percakapan sehari-hari untuk itu pasti dalam komunikasinya masyarakat pasti menggunakan ragam bahasa kolokial.

Dilihat dari segi teori yang sudah dipaparkan di Bab sebelumnya, ragam bahasa merupakan salahsatu poko kajian sosiolinguistik yang mengartikan cirri-ciri bahasa sosial yang ada korelasinya dengan masyarakat sebagai pengguna bahasa tersebut. Ada beberapa unsur komunikasi yaitu ada pembicara, pendengar, topik pembicaraan, tempat terjdinya pembicaraan atau percakapan, suasana percakapan dal nain-lain. Unsur-unsur tersebut sejalan dengan yang terjadi di Kecamatan Pakisjaya Kabupaten Karawang. Masyarakat Pakisjaya mempunyai ragam bahasa yang digunakan karena sesuai dengan kelima unsur komunikasi di atas, masyarakatnya menyesuaikan bahasa sesuai dengan unsurunsur tersebut, misalnya ketika mewawancarai partisipan yang berbahasa Betawi, peneliti menggunakan bahasa Sunda lalu partisipan menggunakan bahasa Sunda sesuai kemampuannya, ketika ada yang tak bisa dia ungkapkan dalam bahasa Sunda maka partisipan langsung merubah bahasanya ke dalam bahasa Indonesia untuk mengurangi kesalahpahaman. Untuk itu dalam komunikasinya masyarakat menyesuaikan dengan siapa dia berbicara, apa isi pembahasannya dan dimana dia berbicara.

Selain itu, ragam bahasa yang muncul akibat dari kelima unsur tersebut dirasa sangat penting, misalnya dalam ragam bahasa argot. Ragam bahasa argot adalah ragam bahasa yang digunakan dalam profesi tertentu, untuk itu ragam bahasa argot tergantung pada tempat penggunaannya seperti pedagang yang ada di pasar, ragam bahasa argot mereka keluar ketika berbicara dengan sesama pedagang disana. Hal ini menunjukan adanya unsur tempat dan situasi dalam komunikasi. Selain itu unsur komunikasi yaitu situasi pembicaraan juga jelas terlihat dalam ragam bahasa kolokial. Ragam bahasa 
kolokial adalah ragam bahasa yang digunakan dalam percakapan sehari-hari, dalam komunikasi sehari-hari tentunya pembicara lebih mempertimbangkan situasi pembicaraan, karena dengan situasi yang santai dan akrab lebih memungkinkan masyarakatnya menjalin komunikasi dengan bahasa yang ringan seperti bahasa kolokial yang biasa mereka gunakan sehari-hari. Unsur selanjutnya adalah pembicara dan lawan bicara, unsur komunikasi ini akan muncul tergantung dari siapa yang berbicara dan lawan bicaranya. Misalnya dalam penelitian ini ditemukan satu data kata $P R$ yang terdapat di profesi guru dan siswa, data tersebut memungkinkan ada didua profesi karena pemakainnya saling berkaitan satu sama lain. Untuk itu tidak semua data yang ada di tiap profesi hanya ada di satu profesi, semua data memungkinkan muncul di profesi lain tergantung unsur komunikasi mana yang dibutuhkan.

Pada pembahasan alih kode dan campur kode ini kita akan kaitkan apa penyebab terjadinya alih kode dan campur kode. Untuk itu seperti yang sudah dijelaskan dalam teori faktor yang menyebabkan alih kode yaitu (1) pembicara, (2) lawan bicara, (3) berubahnya situasi karena adanya orang ketiga, (4) berubahnya situasi formal ke non formal atau sebaliknya, dan (5) berubahnya topik pembicaraan. Dari hasil analisis hasil penelitian, dari 36 data alih kode yang ditemukan faktor penyebab terbanyaknya adalah pembicara dan lawan bicara yang menyebabkan alih kode. Hal ini jelas dikarenakan masyarakat Pakisjaya yang berbahasa ibu bahasa Betawi, jadi ketika peneliti menggunakan bahasa Sunda untuk mengukur kemampuan berbahasanya partisipan kebanyakan berakih kode ke bahasa Betawi dengan alasan sedikitnya pembendaharaan kata dalam bahasa Sunda. Sama dengan alih kode, campur kodepun memiliki faktor penyebabnya yaitu (1) kebiasaan menggunakan bahasa sehari- hari, (2) membutuhkan sinonim untuk menambah kata, (3) ada keinginan untuk menafsirkan, dan (4) situasi informal. Dalam penelitian ini factor yang menyebakan adanya campur kode adalah kebiasaan masyarakat menggunakan bahasa sehari-hari. Karena masyarakat Pakisjaya sehari-hari menggunakan bahasa Betawi, ketika berbicara bahasa Sunda atau Indonesia mereka sering tidak sadar menggabungkan unsur kode bahasa Betawi, begitupun juga karena menggunaan bahasa Sunda, indonesia dan betawi dalam satu lingkungan terkadang membuat mereka tidak sadar mencampur kode-kode ketiga bahasa tersebut.

\section{SIMPULAN}

Ragam bahasa yang ditemukan di Kecamatan Pakisjaya Kabupaten Karawang ada enam ragam bahasa yaitu akrolek, basilek, kolokial, argot, slang, dan jargon. Ragam bahasa akrolek ditemukan di profesi guru, pegawai pemerintah, petani, dan tokoh agama. Ragam bahasa basilek hanya ditemukan di profesi petani. Ragam bahasa kolokial ditemukan di profesi guru, siswa, pegawai pemerintah, petani, pedagang, tokoh agama, dan nelayan. Ragam bahasa argot ditemukan di guru, siswa, pegawai pemerintah, petani, pedagang, tokoh agama, dan nelayan. Ragam bahasa slang ditemukan di profesi pedagang dan siswa. Terakhir Ragam bahasa jargon hanya ditemukan di profesi pegawai pemerintah. Ragam bahasa yang tidak ditemukan dalam penelitian ini adalah ragam bahasa ken dan ragam bahasa vulgar.

Dari data tersebut didapat faktor penyebabnya adanya ragam bahasa yaitu karena letak georgrafisnya yang berbatasan langsung dengan wilayah lain dan kebutuhan masyarakat dalam komunikasi, hal ini juga yang menyebabkan adanya alih kode dan campur kode di masyarakat Pakisjaya. Keragaman bahasa dan budaya menjadi faktor yang sangat kuat timbulnya 
tiga bahasa di Pakisjaya, untuk itu dalam penggunaanya masyarakat menyesuaikannya sesuai unsur komunikasi yang dibutuhkan seperti situasi, tempat, topik, waktu dan dengan siapa mereka berkomunikasi.

\section{PUSTAKA RUJUKAN}

Chaer \& Leonie Agustina. (2004). Sosiolinguistik: Perkenalan Awal. Jakarta: Rineka Cipta.

Hudson, Richard Anthony. (1998). Sosisolinguistik. Bandung: Yayasan amal Keluarga.

Kridalaksana. (2009).Kamus Linguistik. Jakarta: PT. Gramedia.

Maleong, M.A Lexy. J. (2007). Metodologi Penelitian Kualitatif. Bandung: Rosda.

Nababan, P.J.W. (1991). Sosiolinguistik: Suatu Pengantar. Jakarta: Gramedia Pustaka Utama.
Pateda, Mansoer. (1987). Sosiolinguistik. Bandung: Angkasa.

Ratna, N.K. (2011). Teori, Metode dan Teknik Penelitian Sastra. Yogyakarta: Pustaka Pelajar.

Sudaryat, Yayat. (2004) Elmuning Basa. Bandung: Walatra.

Suwito. (1983). Pengantar Awal Sosiolinguistik: Teori dan Problem. Surakarta: Fakultas Sasrta Universitas Sebelas Maret.

Suyanto \& Sutinah. (2006). Metode Penelitian Sosial. Jakarta: Kencana.

\section{UCAPAN TERIMA KASIH}

Penulis menyampaikan rasa terima kasih kepada tim penyunting Jurnal Lokabasa yang telah berkenen memuat tulisan ini. Iidak lupa penulis menyampaikan terima kasih dan penghargaan setinggi-tingginya kepada semua pihak yang telah membantu terlaksananya penelitian ini. 